\title{
Ranking Tool Created for Medicinal plants at Risk of Being Overharvested in the Wild
}

\author{
Lisa Marie Castle ${ }^{1 *}$, Susan Leopold ${ }^{2}$, Rachel Craft ${ }^{3}$, Kelly Kindscher ${ }^{3}$ \\ Author address: ${ }^{1}$ Southwestern Oklahoma State University, Department of Biological Sciences, 100 Campus Drive, Weather- \\ ford, OK $73096{ }^{2}$ United Plant Savers, PO Box 776, Athens, OH 45701, ${ }^{3}$ Kansas Biological Survey, 2101 Constant Ave., \\ Lawrence, KS 66047 \\ ${ }^{*}$ Corresponding Author: lisa.castle@swosu.edu
}

Received: September 26, 2013

Volume 5:77-88

Published: May 30, 2014

(C) 2014 Society of Ethnobiology

\begin{abstract}
We developed an adaptable, transparent tool that can be used to quantify and compare vulnerability to overharvest for wild collected medicinal plants. Subsequently, we are creating a list of the most threatened medicinal plants in temperate North America. The new tool scores species according to their life history, the effects of harvest, their abundance and range, habitat, and demand. The resulting rankings, based on explicit criteria rather than expert opinion, will make it easier to discuss areas of vulnerability and set conservation priorities. Here we present scores for 40 species assessed using the At-Risk Tool and discuss the traits that led to different scores for six example species: echinacea (Echinacea angustifolia DC. Asteraceae), peyote (Lophophora williamsii (Lem. ex Salm-Dyck) J.M. Coult. Cactaceae), sandalwood (Santalum spp. L. Santalaceae), stinging nettle (Urtica dioica L. Urticaceae), American ginseng (Panax quinquefolius L. Araliaceae) and mayapple (Podophyllum peltatum L. Berberidaceae).
\end{abstract}

Keywords: medicinal plants, sustainable harvest, plant conservation

\section{Introduction}

Competing interests for land use, a growing human population, and a growing herbal products industry place pressure on populations of wild-harvested medicinal plants. As a reaction to these growing threats, the United Plant Savers (UpS) formed in 1995 with a mission to "protect native medicinal plants of the United States and Canada and their native habitats while ensuring an abundant supply of medicinal plants for generations for come" (UpS 2013). One step towards accomplishing this mission was to create lists of medicinal plant species deemed most vulnerable to over-harvest ("At-Risk") and those less vulnerable but still of great concern ("To-Watch").

First officially published in 2000 as part of the United Plant Savers' Planting the Future book (Gladstar and Hirsch), the At-Risk and To-Watch Lists were developed following a long series of discussions that included input from herbalists, ecologists, land managers and herb growers. The listed plants were considered to be sensitive to human activity based on market analysis, habitat specificity, impacts of harvest, and lack of techniques or material for large scale cultivation (Gladstar 2000). Where scientific infor- mation about plant populations was unavailable, the organization deliberately chose to be conservative in their assessments and include species on the list (Gladstar 2000). Plants for which multiple species may be harvested and sold under the same common name (e.g. "Echinacea" or "eyebright") were scored collectively as a genus. As of December 2012, the United Plant Savers At-Risk List included 14 species and 7 genera, while the To-Watch List included 17 species and 5 genera.

The At-Risk and To-Watch Lists immediately filled a unique role in plant conservation. Many other agencies have created lists: the federal Endangered Species Act works to protect the very rarest of species; NatureServe provides a standard ranking system used by all US States to score plant species based on rarity and abundance; and the Convention on International Trade in Endangered Species (CITES) regulates international trade in threatened species. None of these other lists, however, considers issues specific to medicinal plants, including market forces and method of harvest. The At-Risk and ToWatch Lists were therefore widely disseminated and used by different audiences. Governmental agencies, 
conservation organizations, popular media, herb sellers and growers, consumers, and herbalists have all referred to the UpS lists (Cech 1998, Westfall and Glickman 2004, McCoy et al. 2007, Roberson 2008). As use of the lists has expanded, so has recognition of their limitations. Despite a stated desire for the lists to be continuously reviewed and for species to be removed from the lists as the threat of over-harvest is reduced (Gladstar 2000), the difficulties of including input from so many stakeholders made the lists effectively static. Neither additional plants nor additional information could be easily added. Without publicly available criteria, inclusion on the At-Risk List did not provide any information about the factors causing a species to be vulnerable, information about areas of greatest conservation concern, or means of comparing one species to another.

Working with the United Plant Savers, we set out to create a tool to answer these criticisms and better aid in setting conservation priorities for wildharvested medicinal plants. Our primary goal was to create a tool that: 1) meets the needs of the diverse users of the United Plant Savers lists, 2) leads to numerical scores of vulnerability to over-harvest that are comparable across species, 3) is based on explicit, science-based criteria, and 4) is transparent and adaptable such that new information or new plants can be added at any time. Our second goal was to use the assessment tool to score plants and use the numerical scores to inform updates to the At-Risk and To-Watch Lists.

\section{Materials and Methods}

Creation of the Assessment Tool

The format of the assessment tool was patterned after the Blue Oceans Group's Seafood Mini Guides (Brownstein et al. 2003). As with susceptibility of seafood to over-fishing, vulnerability to over-harvest depends on many different factors, from intrinsic life history traits to market forces. Based on literature, logic, and discussions with conservation practitioners, five main factors that influence a species' vulnerability to overharvest were determined: life history, effect of harvest on individual plants, population size, habitat, and demand (Peters 1994, Cunningham 2001, Schippmann et al. 2002, Schippmann et al. 2006). While it was recognized that each of these factors is important, it was impossible to quantify their relative importance, so like the seafood assessment or
Rabinowitz's "seven forms of rarity" (1981), we considered each factor equally. The At-Risk Assessment Tool is divided into five sections based on these factors. Each section begins with a broad multiple choice question that leads to a score of 4 to 12 points, which is then modified by three to five questions that can add or subtract up to two points each. The range for point values was selected for ease of use with integer values and whole number totals. Absolute magnitude of the scores is not meaningful outside of the context of the tool. The complete list of main and modifying questions and their associate point values can be found on The At-Risk Assessment Tool in Appendix A. A species' score is the sum of all the section scores and the higher the point total, the more vulnerable the plant species is to overexploitation.

The questions in each section are discussed below.

\section{Life History section}

This group of questions assesses how quickly a plant can grow and spread. For example, a long-lived perennial that is destructively killed when harvested will score 12 points for life history, while a harvested annual will score only 4. Vegetative reproduction in the wild will decrease this score, and the necessity of a specialist pollinator will increase it.

\section{Effect of Harvest on Individuals section}

This group of questions will produce higher scores for plant species that are root harvested rather than those for which the leaves are used. Re-sprouting or quick recovery will decrease this score and a long harvest season (thus being open to year round exploitation) will increase it.

\section{Population Size section}

These questions' scores will primarily be determined by the extent and density of naturally occurring populations. The size of the range and habitat specificity modify this section score.

\section{Habitat section}

The main question in this section is about the vulnerability and extent of a plant species' habitat. Habitats that are both limited and specifically threatened score 12 points, and habitats that are widespread and no more threatened than all natural areas score 4. Modifying questions concern fragmentation, soil type, and particular habitat threats (e.g. urbanization, logging, invasive species). 


\section{Demand section}

These questions' scores will primarily be determined by the annual demand for wild harvested plant product. Availability of widely accepted substitutes and ease of cultivation will decrease this score, while unique uses and failed past attempts at cultivation will increase it.

The process of refining the list of questions was collaborative and iterative. At each stage, plant ecologists and medicinal herbs specialists were asked to independently score plant species. Areas where scores were most divergent were noted and discussions ensued about whether the differences were due to incomplete information or different interpretations of the questions. After several rounds of scoring and discussion, a committee of 14 met in person in July 2005 for an At-Risk Tool Review meeting at HerbPharm in Williams, Oregon. At this time, we placed quantitative bounds on question responses (e.g. that high demand is more than 10 tons dry weight collected annually in the United States, or that a large range extends more than 300 miles) and questions for which the answers are unknown for most species (e.g. seed bank details, or how disturbance affects reproductive output) were removed from the tool. We recognized that one of the weaknesses of the tool is that good data on the actual number of plants, seed produced, and other reproductive characteristics do not exist for most species of medicinal plants.

\section{Selection of Species and Scoring}

All of the taxa on the United Plant Savers At-Risk or To-Watch Lists as of October 2012 were scored using the tool. Stinging nettle (Urtica dioica L. Urticaceae) and elderberry (Sambucus canadensis L. Caprifoliaceae) were also scored because we wanted to include species that likely (and did) have low scores because they were not at risk. Each species was independently assessed by at least three scorers who work in the field of plant ecology. Many species were also assessed by undergraduate students in plant science classes at Glenville State College and Southwestern Oklahoma State University as part of an assignment investigating medicinal plants and internet information retrieval. To assess a species, the scorer enters the point value for each main and modifying question on a score sheet. The score sheet also contains a space for the scorer to enter a note about the relevant knowledge for that question and a space to identify the source of that knowledge. Where possible, scorers relied on primary and well-documented secondary source information including the North Carolina Consortium on Natural Medicines Grower's Guides, the USDA Plants Database and the American Herbal Products Association Tonnage Reports (Greenfield and Davis 2004, USDA, NRCS 2013, Dentali and Zimmerman 2012). Where better-documented data were unavailable, plant information was also gleaned from web pages of wildcrafters, retail herbal companies, and home gardeners.

"Master Scores" for each species were assigned by Kindscher or Castle. To do this, all of the independent score sheets were compiled and a score for each question was assigned based on the consensus responses from the individual score sheets or from reconciling differences based on source data.

\section{Results}

Scores on the 40 species assessed ranged from a low (least vulnerable to overharvest) of 8 for nettles ( $U$. dioca) to a high (most vulnerable to overharvest) of 75 for sandalwood (Santalum paniculatum Hook \& Arn. Santalaceae and related species) (Figure 1). The most vulnerable species scored, including sandalwood, had high scores in all five areas assessed. Many species on the original At-Risk List had high scores for several categories, but not for all, which highlights different areas of greatest concern for different species.

Collectively, those species on the 2012 At-Risk List had higher average scores than those on the 2012 To-Watch List and those on the To-Watch List had higher average scores than the species assessed that were not listed by United Plant Savers. Many individual species from the 2012 To-Watch List, however, scored higher than some individual species originally deemed At-Risk, which indicates a need to examine the dividing line between At-Risk and To-Watch.

\section{Discussion}

Case studies of species on the At-Risk List

The following case studies present a range of species that were scored with the ranking tool.

1) Eastern Deciduous Perennials: American Ginseng (Panax quinquefolius L. Araliaceae), score of 63, and Mayapple (Podophyllum peltatum L. Berberidaceae), score of 34

Many of the species on the original At-Risk List are herbaceous perennials from the understory of the deciduous forest in the Eastern United States and Canada. Most of these species are long-lived and harvested for root or rhizome use (Klein 2000), giving 


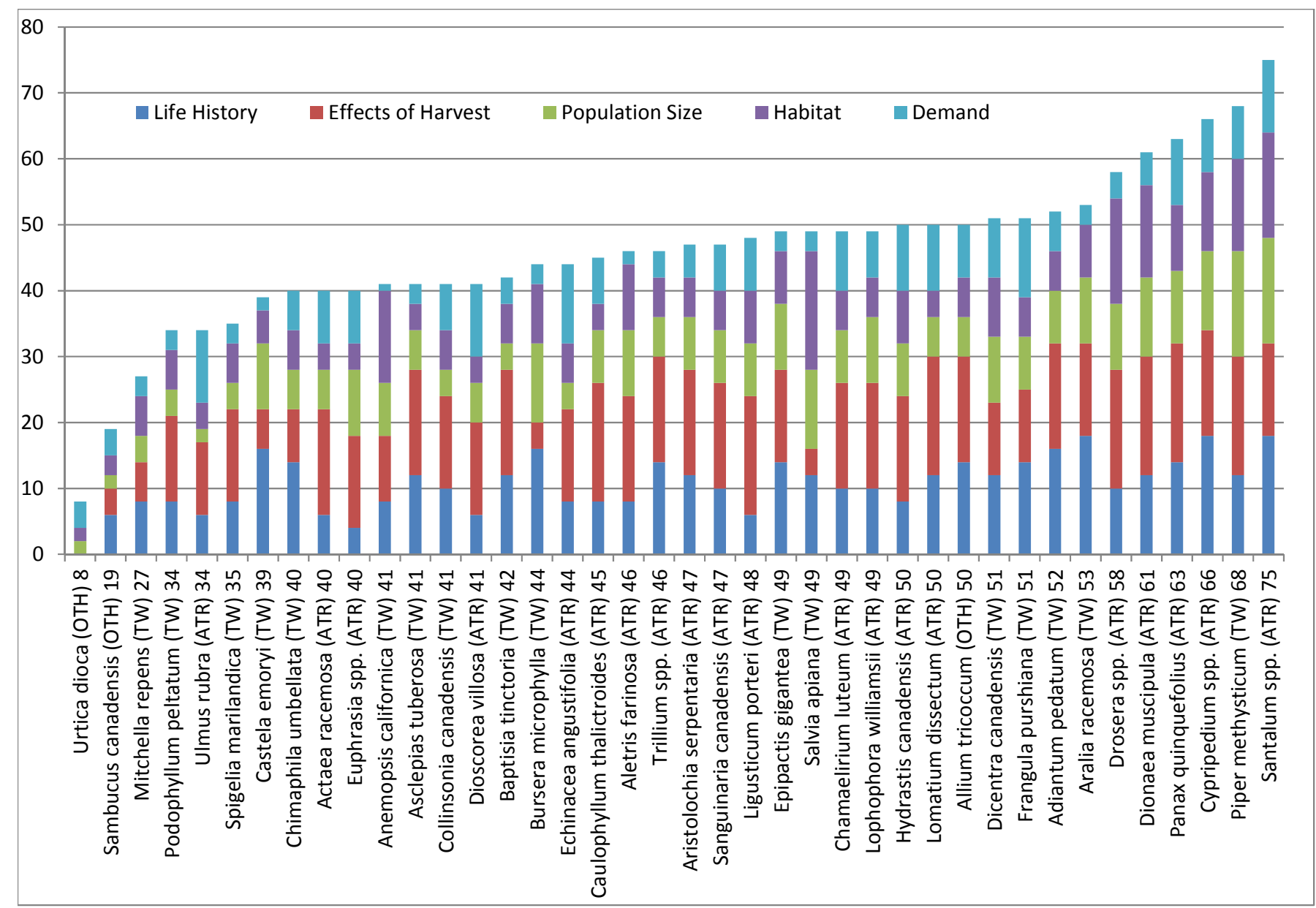

Figure 1. Scores of species and genera scored using the At-Risk Tool. Parentheses indicate previous listing by the United Plant Savers (as of December 2012) as At-Risk (ATR), To-Watch (TW) or unlisted ("Other", OTR). Colored regions indicate magnitude of the subscores for life history, effects of harvest on individuals and populations, population size, habitat, and demand.

them high scores for the main questions in life history and effects of harvest on individuals, yet the overall scores can be quite different.

Comparing mayapple (overall score of 34) with American ginseng (overall score of 63) highlights the areas in which two perennial species from the same woodlands can differ. Mayapples can thrive along roadsides, spread rhizomatously, and are easy to grow in a garden setting, decreasing their life history score compared with disturbance intolerant ginseng. While both species have a naturally wide range, covering hundreds of kilometers, ginseng patches are much less dense and more difficult to find than mayapple patches. Adverse effects of the plant-killing harvest on population size and structure in ginseng populations have been documented (McGraw 2001, Mooney and
McGraw 2009, Rock et al. 2012), thereby increasing the relative vulnerability of ginseng to overharvest.

Both mayapple and ginseng live in a habitat of fairly stable size that is threatened by invasive species, overgrazing by deer, and expanded human development. Impacts of these habitat changes on ginseng populations have been studied and documented (McGraw and Furedi 2005, Wixted and McGraw 2010). Mayapple populations, frequently visible from roadsides, appear less disturbed by these habitat changes; but, as with most medicinal plant species, effects of habitat changes on the populations have not been directly studied.

Demand for ginseng remains high and, although cultivation is possible, wild-harvested roots continue 
to sell at a considerable premium (Hankins 1998, Chamberlin et al. 2013). The demand for mayapple, meanwhile, is low: a recent internet search found many more retailers selling plants for ornamental garden use than selling medicinal mayapple products in any form. While no long-lived perennial harvested for roots or rhizomes is invulnerable to overharvest, mayapple exhibits traits that make it considerably less vulnerable than American ginseng.

\section{2) Nettle (Urtica dioica), score of 8}

Stinging nettles is a well-known herb that is common in moist soil and waste places. Its low score suggests it is not at risk of over-harvest and it exemplifies many of the traits of species for which wild harvest is not currently of conservation concern. It is a perennial that reproduces the first year from seed, spreads by rhizomes, and is almost invasive. As only the leaves and stems are generally collected, harvest does not impact the population much. A nettle patch can be harvested more than once per year, and certainly every year as it re-grows easily. The plant is naturally abundant with a large range and many dense populations that appear to be stable, and painful to harvest, across its range. Its specific habitat is not threatened and there are large areas of low, moist waste ground along creeks and streams. Finally, although the annual demand for nettles is moderate, the plant is high yielding and can easily be cultivated. Overall this plant is not at risk for being over-harvested.

\section{3) Sandalwood (Santalum spp.), score of 75}

Native Hawaiian sandalwood is vulnerable to overharvest and possibly at risk of extinction due to the fact that it takes more than 40 years to mature, and harvesting involves removing the entire tree. Furthermore the sandalwood tree is a hemi-parasite species that needs certain host plants in order to grow, making it a tricky species to reforest successfully. Sandalwood's extraordinary fragrance, versatility, and medicinal properties have put it in high demand for centuries, all over the world. This is why Hawaii's native sandalwood population was almost completely decimated during the infamous sandalwood trade that took place during 1815-1825. Despite this history, Hawaii remains the only region in the world where sandalwood is commercially harvested without regulation. Native Hawaiian sandalwood represents a quarter of the diversity of the genus Santalum. Six separate species are found throughout the Hawaiian Islands, and within these species are several unique varieties, all endemic to the Islands. One variety, Santalum freycinetianum var. lanaiense Rock, has already been officially recognized as endangered (USDA, NRCS 2013). Currently, S. paniculatum is the only species that is currently commercially harvested on the Big Island (Tummons 2010).

Sandalwood was placed on the UpS At-Risk List by a board vote in 2011. After hearing concerns about exploitation of sandalwood in Hawaii, UpS members scored the plant using a draft version of the tool, and then came to the consensus decision to add Sandalwood to the At-Risk List. It is the only taxon that has been added to the list after being scored with the tool.

Sandalwood has a high life history score as it is a long-lived tree that does not reproduce easily. It scored high on effects of harvest on populations because the entire plant is harvested, many plants do not re-grow, and for those that do, they are slow growing. It scored very high in abundance and range, which are both very limited due to limited habitats on an island. The habitat of native sandalwood is both scarce and threatened. Finally, sandalwood scores high in demand because there is a large market for the volatile oil and no commercial cultivation exists in the US. Overall, sandalwood, with a score of 75 , exemplifies all of the traits of a plant species at great risk of being over-harvested.

4) Echinacea (Echinacea angustifolia DC. Asteraceae), score of 44

The Echinacea genus in North America includes nine species with very different ranges and medicinal use patterns. The most popular medicinal Echinacea is E. angustifolia, which is primarily harvested in the wild (Price and Kindscher 2007; Kindscher et al. 2008). Also in the genus are Ecbinacea purpurea (L.) Moench, which is widely cultivated, and two species that have been listed as threatened or endangered (E. sanguinea Nutt. and E. tennesseensis (Beadle) Small). To clarify assessment, we are considering Echinacea species separately, rather than as a collective genus as originally listed on the At-Risk List. We have scored only E. angustifolia here, but caution that E. sanguinea and E. tennesseensis, because of their small population sizes and limited ranges, are species more vulnerable to overharvest.

The life history score for E. angustifolia is low to moderate because, although it is a long-lived perennial, it tolerates disturbance, produces lots of seeds, and most interesting, half of the harvested plants are able 
to re-sprout after the top 6-10 inches $(15-25 \mathrm{~cm})$ of root is harvested (Kindscher et al. 2008). The score for "Effects of Harvest" is high because roots are harvested (which can kill the plant), it takes years for plants to be large enough to harvest, harvest is conducted nearly year-round, and, when recovery from harvest occurs, it takes several years for the roots to be large enough for harvest again. The abundance and range score is very low because many scattered populations exist over a large range of Great Plains states and E. angustifolia can grow in many broad habitats, although some populations have been decreasing due to grazing, herbicide use, and other land management practices. The habitat vulnerability score is moderately low as the rocky prairie habitat is widespread and not particularly threatened. Since the great plowing of prairies occurred, habitats have remained generally available with no special threats, and the plants do not require any unique soil type. The demand score is moderately high as market demand is high, but yield per acre is moderate, and cultivated sources are known and available. Overall, E. angustifolia, with a score of 44 , has only a moderate risk of being over-harvested.

5) Peyote (Lophophora williamsii, (Lem. ex SalmDyck) J.M. Coult. Cactaceae), score of 49

L. williamsii, or peyote, is an unusual medicinal plant as it is not legal for most people to harvest or possess it, yet it is a central part of a Native American sacrament. There is considerable concern about the over-harvest of this plant due to its limited range, the tightening of trade across the Mexican border, and the growth of the Native American Church (Terry et al. 2011). Peyote scores high on life history as it is a longlived cactus that produces slowly, but it does vegetatively propagate and tolerate some disturbance. It also scores high on the effects of harvest because either crowns or whole plants are collected and the harvest season is very long. When the crowns are harvested, regrowth takes at least four years (Terry, personal communication January 2013; Terry et al., 2011). As for abundance and range, it has a moderately high score as populations are not dense, most of the large range is in Mexico and inaccessible to US harvesters, and population declines have been documented. Peyote's main habitat score is fairly low, as its habitat is widespread and has not changed greatly over the last decades. Modifying questions increase this section score because the plant is only found on calcareous soil and the habitat is threatened by invasive species and development. The highly regulated market keeps legal demand low, but the demand section score is increased because the yield per acre is less than 10 pounds, no substitutes are acceptable, and it is not currently commercially cultivated.

\section{Conclusions: Applications and Limitations}

We believe that the At-Risk Tool can be a useful method of summarizing a plant species' vulnerability to over-exploitation and will be helpful for setting conservation priorities. The tool does not provide a clear numerical cut-off between species that warrant protection and species that can be harvested without concern. It does, however, provide a snapshot of relative vulnerability based on magnitude of total score, and a quick synopsis of areas of greatest concern based on the subscores.

Additional Influences on Vulnerability and Missing Information

We recognize that other factors not included in the tool may influence a species' vulnerability and these circumstances will require broader discussion. We also recognize that the information on plant populations, habitats, and demand, that are required to use the tool, are not always well documented and are rarely available in the same form across species. While this lack of consistent baseline data highlights a limitation of the tool, it also demonstrates an important secondary function of the tool: use of the tool requires a compilation of available information into one place and draws attention to areas where data is entirely lacking. Such gaps in knowledge can be the starting point for future studies, and use of the tool brings them to light. An important attribute of the tool is that it is adaptable to new information and that scores can be easily updated or generated as new information is learned or conditions change.

\section{Using Scores and the At-Risk. Tool}

We are hopeful that, like the original At-Risk and ToWatch Lists, the new scores will be used by a wide range of audiences, from land management organizations setting conservation priorities to herbalists recommending appropriate alternatives to the most vulnerable herbs. The availability of subscores for each area should aid in planning and decision-making. For example, even though they both score 49, different strategies should be employed to protect white sage (Salvia apiana Jeps. Lamiaceae), which has a highly threatened habitat in the southern California desert and moderate demand for leaves, than to 
protect the stream orchid (Epipactis gigantea Douglas ex. Hook. Orchidaceae), which has low demand but an inherently more vulnerable life history, being a water-loving perennial orchid.

The tool can be used to quickly model how potential changes might affect a species' vulnerability. If a plant were determined next year to be the next Viagra, only better, then the At-Risk Tool could be used to determine to what degree we should be concerned about its potential overharvest. It can also be used to project effects of changes in range and habitat due to climate change, invasive species or urban expansion.

\section{Opportunities for Expansion}

One current limitation of use of the tool is small sample size of plants scored. Scores would be of greater value if they could be compared to scores from a broader sample of medicinal plants. We heartily encourage others interested and knowledgeable about medicinal plants in North America to assess plants using the At-Risk Tool and submit the results and comments to the United Plant Savers.

While designed for wild-harvested medicinal plants in temperate North America, the questions on the At-Risk tool can apply to many other groups of plants and regions with only slight modifications to questions. The tool can also serve as a dynamic teaching instrument for students and the general public who are concerned about wild plant populations. As use of the At-Risk Tool expands to other species and other regions, we anticipate productive discussions for adjustments to provide scores that will best inform practitioners working with the goal of sustainable plant populations.

\section{Acknowledgements}

There are many people who have helped with developing this tool. The At-Risk List was developed by the United Plant Savers, and their staff and board over the years have been instrumental in maintaining and promoting the list. The current board also requested that we work on this tool and provided some funds for its development. Among those on the board and staff, advisory board, and others who have helped, are: Beth Baugh, Tim Blakely, David Bunting, Richo Cech, Jim Chamberlain, Trish Flaster, Edward Fletcher, Steven Foster, Cascade Anderson Geller, Rosemary Gladstar, Mindy Green, Christopher Hobbs, Gary Kauffman, Sara Katz, Lynda LeMole, Michael McGuffin, and
Mark Wheeler. Hillary Loring, Quinn Long, Jennifer Moody, and students from Glenville State College 2007 and 2009 Botany classes and Southwestern Oklahoma State University 2012 Plant Taxonomy all scored individual plant species. Zella Classen assisted with data management and fact checking.

\section{Declarations}

Permissions: None declared.

Sources of funding: The United Plant Savers provided funds to Kindscher, Castle, and their students to meet, print posters, and complete the project.

Conflicts of interest. Susan Leopold is employed by the United Plant Savers.

\section{References Cited}

Brownstein, C., M. Lee, and C. Safina. 2003. Harnessing Consumer Power for Ocean Conservation. Conservation Magazine 4:39-42.

Cech, R. A. 1998. Balancing Conservation with Utilization: Restoring Populations of Commercially Valuable Medicinal Herbs in Forests and Agroforests. Paper presented at the North American Conference on Enterprise Development through Agroforestry. Minneapolis, MN, October 4-7.

Chamberlain, J. L., S. Prisley, and M. McGuffin. 2013. Understanding the relationships between American ginseng harvest and hardwood forests inventory and timber harvest to improve co-management of the forests of eastern United States. Journal of Sustainable Forestry (in press).

Cunningham A. B. 2001. Applied Ethnobotany: People, Wild Plant Use, and Conservation. Earthscan Publications, London, UK.

Dentali, S. and M. Zimmermann. 2012. Tonnage Surveys of Select North American Wild-Harvested Plants, 2006-2010. American Herbal Products Association. Silver Springs, MD.

Gladstar, R. 2000. Introduction. Pp. 1-12 in Planting the Future, edited by R. Gladstar and P. Hirsch. Healing Arts Press, Rochester, VT.

Gladstar, R. and P. Hirsch. 2000. Planting the Future. Healing Arts Press, Rochester, VT.

Greenfield, J. and J. Davis. 2004. Medicinal Herb Production Guides. North Carolina Consortium on Natural Medicines and Public Health. North Carolina State University, Raleigh, NC. 
Hankins, A. 1998. Producing and marketing wild simulated ginseng in forest and agroforestry systems. Paper presented at the North American Conference on Enterprise Development through Agroforestry. Minneapolis, MN, October 4-7.

Kindscher, K., D. M. Price, and L. Castle. 2008. Resprouting of Echinacea angustifolia Augments Sustainability of Wild Medicinal Plant Populations. Economic Botany 62(2):139-147.

Klein, R. 2000. Wise Old Plants. Pp. 24-38 in: Planting the Future, edited by R. Gladstar and P. Hirsch. Healing Arts Press, Rochester, VT.

McCoy, J. A., J. M. Davis, N. D. Camper, I. Khan, and A. Bharathi. 2007. Influence of Rhizome Propagule Size on Yields and Triterpene Glycoside Concentrations of Black Cohosh [Actaea racemosa (L.) Syn Cimicifuga racemosa (L.) nuttal]. HortScience 42 (1): 61-64.

McGraw, J. B. 2001. Evidence for Decline in Stature of American Ginseng Plants from Herbarium Specimens. Biological Conservation 98:25-32.

McGraw, J. B. and M. A. Furedi. 2005. Deer Browsing and Population Viability of a Forest Understory Plant. Science 307(5711):920-922.

Mooney, E. H. and J. B. McGraw. 2009. Relationship Between Age, Size and Reproduction in Populations of American Ginseng, Panax quinquefolius (Araliaceae), Across a Range of Harvest Pressures. Ecoscience 16 (1): 84-94.

Peters, C. M. 1994. Sustainable Harvest of Non-timber Plant Resources in Tropical Moist Forest: An Ecological Primer. The New York Botanical Garden, Bronx, NY.

Price, D. H. and K. Kindscher. 2007. One Hundred Years of Echinacea angustifolia Harvest in the Smoky Hills of Kansas, USA. Economic Botany 61:8695.

Rabinowitz, D. 1981. Seven forms of rarity. Pp 205217 in: The biological aspects of rare plant conservation. Edited by J. Synge. Wiley, New York.

Roberson, E. 2008. Medicinal Plants at Risk. A Native Plant Conservation Campaign Report. Center for Biological Diversity. Tucson, AZ.

Rock, J., G. Kauffman, and N. Murdock. 2012. Harvesting of Medicinal Plants in the Southern Appalachian Mountains. Journal of Medicinal Plant
Conservation. Winter 2012: 12-13.Schippmann U., D. Leaman, and A. B. Cunningham. 2006. A Comparison of Cultivation and Wild Collection of Medicinal and Aromatic Plants Under Sustainability Aspects. Pp. 75-95 in Medicinal and Aromatic Plants, edited by R.J, Bogers, L.E. Craker, and D. Lange. Wageningen UR Frontis Series, Vol. 17. Springer, Dordrecht, the Netherlands.

Schippmann U., D. J. Leaman, and A. B. Cunningham. 2002. Impact of Cultivation and Gathering of Medicinal Plants on Biodiversity: Global Trends and Issues. In Biodiversity and the Ecosystem Approach in Agriculture, Forestry and Fisheries. Inter-Departmental Working Group on Biological Diversity for Food and Agriculture, FAO, Rome.

Terry, M., K. Trout, B. Williams, T. Herrera, and N. Fowler. 2011. Limitations to natural production of Lophophora williamsii (Cactaceae) I. Regrowth and survivorship two years post harvest in a South Texas population. Journal of the Botantical Research Institute of Texas 5:661-675.

Tummons, P. 2010. Dispute Over Hokukano Sandalwood Logging Ends Up Before Federal Bankruptcy Judge. Environment Hawaii 21:1.

Westfall, R. E. and B. W. Glickman. 2004. Conservation of Indigenous Medicinal Plants in Canada. In Proceedings of the Species at Risk 2004 Pathways to Recovery Conference, edited by T. D. Hooper. Species at Risk 2004 Pathways to Recovery Organizing Committee, Victoria, B.C.

UpS. 2013. The United Plant Savers Homepage (http://www.unitedplantsavers.org/, accessed 9 Sept. 2013). East Barre, VT, USA.

USDA, NRCS. 2013. The PLANTS Database (http://plants.usda.gov, accessed 1 July 2013).National Plant Data Team, Greensboro, NC 27401-4901 USA.

Wixted, K. L. and J. B. McGraw. 2010. Competitive and Allelopathic Effects of Garlic Mustard (Alliaria petiolata) on American Ginseng (Panax quinquefolius). Plant Ecology 208:347-357.

\section{Biosketch}

Lisa Marie Castle investigates plant-human interactions and teaches as an assistant professor of biology at Southwestern Oklahoma State University. 
Susan Leopold is Executive Director of United Plant Savers and serves as board member of Botanical Dimensions and the Center for Sustainable Economy.

Rachel Craft is a PhD Candidate at the University of Kansas, Department of Sociology, and a Graduate Research Assistant at the Kansas Biological Survey.
Kelly Kindscher is a plant ecologist at the Kansas Biological Survey and a professor in the Environmental Studies Program at the University of Kansas. 


\title{
Appendix A: United Plant Savers At-Risk Assessment Tool
}

\author{
I. Life History: How vulnerable are plants based on their life history? \\ 1. Life span \\ +4 Annual or Biennial (1-2 years) \\ +4 Perennial Plant that is not destructively harvested \\ +8 Short Lived Perennial (2-5 years) \\ +12 Long Lived Perennial (> 5 years) \\ 1.1 Age at first reproduction \\ -21 or less \\ 02 to 4 \\ $+2 \quad 5$ or more
}

1.2 Ability to withstand disturbance (e.g. ability to grow after vegetation and soil have been mowed, plowed, grazed or otherwise disturbed)

-2 Thrives on disturbance (weedy or early succession species)

0 Tolerates some disturbance or some types of disturbances

+2 Intolerant (very conservative species)

1.3 Ability to reproduce vegetatively under normal conditions

-2 Reproduces vegetatively regularly in the wild and from small parts of plant (includes suckers, runners, bulblets and tubers)

$0 \quad$ Occasionally reproduces vegetatively in the wild

+2 Rarely to never seen to reproduce vegetatively in the wild

1.4 Ability to reproduce from seed under normal conditions

-2 Seedlings regularly seen or easy to cultivate from seed

0 Seedlings occasionally seen

+2 Seedlings rarely to never seen

1.5 Interactions with other organisms required for growth and reproduction (e.g. known obligatory mychorrhizal associations, pollinator specificity, parasitism)

-2 No special associations needed to grow it in places outside of natural range

$0 \quad$ Not known

$+2 \quad$ Known limiting associations

\section{Effects of Harvest on Individuals and Populations: How does harvest affect plants?}

2. Part of plant most commonly harvested

+4 Harvest is of leaves and twigs only.

+8 Harvest is of seeds, fruits, flowers, stem bark or off-shoots.

+12 Harvest is of roots, root bark or entire plant.

\subsection{Post-Harvest Recovery of Individual Plants}

-2 Plants are able to reproduce normally the season following harvest.

$-1 \quad$ Harvest limits the next season's growth

$0 \quad$ At least some plants in a harvested population can re-grow after harvest, but re-growth takes several growing seasons

+2 Individual plants cannot re-grow after harvest 


\subsection{Harvest Interval}

$-2 \quad$ A plant can be harvested multiple times in one year

$0 \quad 1$ to 2 years

+23 years or more

\subsection{Length of Harvest Season}

$-2 \quad$ Harvestable for one month or less

$0 \quad$ Harvestable for 1 to 3 months

+2 Harvestable for more than 3 months per year

\section{Population Size: How many plants are there?}

3. Is the plant naturally abundant?

+4 Many dense populations exist. (There are many populations in which someone could harvest all day in a very local area.)

+6 A few dense populations exist and many more scattered populations exist. (There are a few populations in which someone could harvest all day without moving and many in which one could harvest all day by moving across some local acreage.)

+8 Many scattered populations exist. (There are many places in which someone could harvest all day by driving to several local patches.)

+10 Few scattered populations exist and many more sparse populations. (There are a few places in which a harvester could harvest all day moving around a bit, but most places the harvester would need to drive distances to harvest all day.)

+12 Populations are few and sparse.

\subsection{Range}

$-2 \quad$ Large (plant found across an area greater than 300 miles)

$0 \quad$ Medium (plant found across an area 100 to 300 miles)

$+2 \quad$ Small (plant found across an area less than 100 miles)

\subsection{Change in overall population size in primary harvest range}

-2 Population known to be increasing

0 Population stable or status unknown

+2 Declines in population size documented

\subsection{Degree of habitat specialization}

-2 Can grow in roadsides, vacant lots or other disturbed areas

$0 \quad$ Can grow in broad habitat categories (e.g. "eastern deciduous forest" or "great plains grassland")

+2 Can only grow in a very limited habitat (e.g. "moist acidic glades in eastern deciduous forest" or "limestone outcrops in tall-grass prairie")

\section{Habitat: How vulnerable is the habitat?}

\section{How vulnerable is the plant's physical habitat?}

$+4 \quad$ Habitat is widespread and no more threatened than all land areas.

$+8 \quad$ Habitat is limited OR specifically threatened

+12 Habitat is limited AND specifically threatened

\subsection{Habitat Acreage Change}

-2 Habitat acreage is expanding (e.g. forest edge, roadsides, "suburban savannas")

$0 \quad$ Habitat acreage unchanged or not dramatically reduced

+2 Habitat acreage has been reduced by $50 \%$ or more over last 100 years. 


\subsection{Habitat Fragmentation}

$-2 \quad$ Large tracts of continuous acres of habitat exist

$0 \quad$ Habitat areas intermediate or unknown

+2 Only very small habitat patches exist

$\underline{4.3 \text { Confined to a limited or very vulnerable soil type }}$

0 No

$+2 \quad$ Yes (includes hydric or salty soils)

\subsection{Habitat Threats}

Add 1 point for each of these habitat threats (to a maximum of 2 points)

\begin{tabular}{|c|c|c|}
\hline $\begin{array}{l}\text { logging expansion rapid development } \\
\text { use land for recreation growing rapidly }\end{array}$ & $\begin{array}{l}\text { mining over-grazing } \\
\text { widespread regular herbicide use }\end{array}$ & $\begin{array}{l}\text { take-over from invasive species } \\
\text { vulnerability to disease }\end{array}$ \\
\hline
\end{tabular}

acid deposition fire suppression

\section{How much is needed?: What is the demand? Are there alternatives? Can the plant be cultivated?}

\section{Annual Demand for Wild Harvested Plant \\ $+4 \quad$ Less than 1 ton dry weight \\ $+8 \quad 1$ to 10 tons dry weight \\ +12 More than 10 tons dry weight}

\subsection{Yield per Acre}

-2 Ten pounds or more

$0 \quad$ One to ten pounds

+2 Less than one pound

\subsection{Availability of good substitute to wild-harvested plant}

-2 Substitute known and widely accepted

$0 \quad$ Substitute known but not widely accepted as such

$+2 \quad$ No known substitutes

5.3 Cultivation and potential for cultivation

$-2 \quad$ Currently cultivated and commercially viable

$-1 \quad$ Not commercially cultivated but cultivation on a commercial scale horticulturally achievable (plant material available, no special associations required)

$0 \quad$ Growth on a commercial scale not easily achievable or economically viable (plant material not available or special associations required)

+2 Growth on a commercial scale probably not achievable (plant material not available AND special associations required) 